\title{
The effect of age at photostimulation of male broiler breeders on testes growth and the attainment of sexual maturity
}

\author{
N.C. Tyler ${ }^{\#}$ and R.M. Gous \\ Animal and Poultry Science, University of KwaZulu-Natal, Scottsville 3209, Pietermaritzburg, South Africa
}

\begin{abstract}
Male broiler breeders were photostimulated at different ages (56, 77, 98, 119, 147 and $161 \mathrm{~d}$ ) during the period of growth prior to achieving sexual maturity to observe their response to photoperiod stimulation. Birds were sampled at regular intervals to measure the average testis weight - these values responding curvilinearly to the age at photostimulation, similar to the attainment of sexual maturity observed previously in females. However, males reached sexual maturity at an earlier age than females, as measured by the start of semen production. Based on the age at first semen production, no differences in the mean age at sexual maturity (ranging from 164 to $172 \mathrm{~d}$ ) resulted from the different ages at photostimulation. Testis weights from males on different photostimulation treatments showed that some males respond to early stimulation, but from $189 \mathrm{~d}$ of age some of these early photostimulated males still had an average testis weight of less than $10 \mathrm{~g}$, while males photostimulated $98 \mathrm{~d}$ and later all had an average testis weight over $10 \mathrm{~g}$. Serum testosterone concentration measured at $351 \mathrm{~d}$ also showed that early photostimulation resulted in two groups of birds that either responded or not. At $351 \mathrm{~d}$ the serum testosterone concentration was more evenly distributed in males photostimulated after $98 \mathrm{~d}$, while males photostimulated before $98 \mathrm{~d}$ had either high or low serum testosterone concentrations. Directional asymmetry was observed in testis weights, with the left testis being bigger than the right. Other bilateral traits measured also showed directional asymmetry, an indication of developmental instability. However, the degree of relative asymmetry was not related to treatment. All males should respond to photostimulation by $98 \mathrm{~d}$ but some respond earlier, and these could be used by broiler breeding companies to eliminate seasonality in these birds.
\end{abstract}

Keywords: Fertility, lighting, testosterone, breeder, cockerel, seasonality

" Corresponding author. E-mail: tyler@ukzn.ac.za

\section{Introduction}

Evidence of juvenile photorefractoriness has been found in broiler breeders reared on different constant daylengths, with the age at sexual maturity (ASM) being delayed in birds reared on long daylengths in both females (Lewis et al., 2004) and males (Tyler \& Gous, 2008). This suggests that photorefractoriness is dissipated at different rates, and that dissipation could occur at a faster rate when broiler breeders are exposed to short daylengths for a period of time. The length of exposure to short daylengths and the age at which birds acquire photosensitivity was previously investigated in female broiler breeders by Lewis et al. (2007). Females photostimulated from 8 to $16 \mathrm{~h}$ light/d at 69, 76, 83 or $97 \mathrm{~d}$ of age did not respond to photostimulation, and dissipation of photorefractoriness was delayed so that birds matured at the same rate as if they had been maintained on long days from hatch, as the delay in ASM was similar to the delay seen in females reared on $16 \mathrm{~h}$ light (Lewis et al., 2004). An advance in ASM was observed when females were photostimulated at 111 and $125 \mathrm{~d}$, but a bimodal distribution was observed when the females were photostimulated at $111 \mathrm{~d}$, as the ASM in some had been advanced while others matured as if reared on $16 \mathrm{~h}$ light/d (Lewis et al., 2007), suggesting that there is some genetic variation in the acquisition of photosensitivity. By $124 \mathrm{~d}$ the entire population had become photosensitive. Robinson et al. (1996) also found a significant delay in ASM when broiler breeders were photostimulated at $160 \mathrm{~d}$ compared to $120 \mathrm{~d}$, but the number of days from photostimulation to sexual maturity was lower in the later-stimulated pullets, indicating that this may not be a photo-induced response. Proudfoot et al. (1984), however, found no significant difference in days to 50\% production of broiler breeder females photostimulated at 112 or $140 \mathrm{~d}$.

Dunn et al. (1990) suggested that the neuro-endocrine pathways involved in the transmission of photoperiodic information are functional at three weeks of age in dwarf female broiler breeders. Photostimulation at three weeks of age, in feed-restricted birds, resulted in significantly higher plasma luteinising hormone (LH) concentrations compared to non-photostimulated control birds. However, this may 
not translate to a different ASM as Lewis et al. (2005) concluded that changes in plasma gonadotrophins were not particularly useful as predictors of ASM, although a photoperiodic response curve, where a plot of the photo-induced increase in plasma LH against a range of photoperiods after photostimulation, is useful in predicting the critical and saturation daylengths (Lewis et al., 2008).

The aim of the experiment reported here was to determine the response of male broiler breeders to different ages at photostimulation, through testes development and asymmetry as well as age at first semen production and serum testosterone concentration, and to determine whether flock fertility may be maximised if males are reared on the same lighting programme as females.

\section{Materials and Methods}

Four hundred Ross broiler breeder males were randomly allocated to 12 light-tight rooms (32 per room) at $56 \mathrm{~d}$ of age after having been reared on a constant 8-h photoperiod. A $60 \mathrm{~W}$ incandescent lamp, located $1.8 \mathrm{~m}$ above the floor, was used to provide a mean illuminance in each room of $47 \pm 1.8$ lux. The birds were photostimulated to $14 \mathrm{~h}$ at 56, 77, 98, 119, 147 and $161 \mathrm{~d}$ of age, each treatment being replicated in two rooms. A controlled feeding programme recommended by the primary breeding company (Aviagen, 2006) was used throughout the growing period, where the average weight of birds in each room was used to allocate feed to keep body weights on the target growth curve. This was in an attempt to minimise the effect of body weight, as there is an expected interaction between body weight and acquisition of photosensitivity where birds become photosensitive earlier when on an accelerated growth curve (Dunn \& Sharp, 1990; Lewis et al., 2007). From 123 to 224 d of age, one or two birds from each room were sacrificed weekly, and the left and right testis were removed and weighed. This time period was to ensure that the range in testis development would be recorded for each treatment. The remaining birds were trained to produce semen using a modified method of Lake (1957), and the age at which birds first produced semen was recorded.

After slaughter, the shanks and wings were removed and frozen for later measurement. After thawing, the bones were boiled to facilitate cleaning, and the following measurements were taken, with vernier callipers, from at least six birds per treatment: shank length (SL), shank diameter (SD) at the narrowest point and humerus length (HL). Relative asymmetry (RA) was defined as the ratio of the absolute value of asymmetry (L-R) divided by the value for the size of the bilateral trait as expressed in the equation:

$\mathrm{RA}=(|\mathrm{L}-\mathrm{R}| /[(\mathrm{L}+\mathrm{R}) / 2]) * 100$ (Yang et al., 1997).

Blood was collected from three males in each room at 123, 130, 137, 158, 168, 197, 224 and $351 \mathrm{~d}$ of age, the serum extracted and frozen for later analysis. After thawing, the serum samples were analysed for testosterone using an enzyme immunoassay kit (DSL-10-4000 Active ${ }^{\circledR}$ Testosterone enzyme immunoassay kit of Diagnostic Systems Laboratories, Inc. 445 Medical Center Blvd. Webster, Texas 77598-4217 USA) which has been validated for use in poultry (Mohan et al., 2002).

Bilateral traits and the left $(\mathrm{L})$ and right $(\mathrm{R})$ testis weights were subjected to a Student's $t$-test to determine whether these bilateral measurements differed significantly one from the other overall, and within each treatment. As the output from the testes is a result of the production from both testes, the average testis weight was used in further analyses. The data for L-R of each bilateral trait were tested for normality using the NORMTEST procedure in Genstat (2008). Regression analysis was performed for L-R testis weight, L-R testis weight RA, L-R SL, L-R SL RA, L-R SD, L-R SD RA, L-R HL and L-R HL RA.

A Gompertz growth curve was fitted to the average testis weights, measured in sampled birds over time, for each treatment, to determine the point of inflexion - the age at most rapid testis growth $\left(t^{*}\right)$. Two outliers in the $77 \mathrm{~d}$ photostimulation treatment were removed to enable a Gompertz curve to be fitted. Genstat (2008) was used for all statistical analyses.

Ethical approval by the University of KwaZulu-Natal Ethics Committee was obtained prior to the start of the experiment.

\section{Results and Discussion}

There was no significant difference between the earliest and latest mean age at first semen production of males on all treatments (Table 1). Males photostimulated at 56 and $77 \mathrm{~d}$, produced semen as early as $133 \mathrm{~d}$. Males photostimulated at $161 \mathrm{~d}$ had a mean age at first semen production earlier than the age at photostimulation (Table 1). Thus, in this case, testis development and spermatogenesis had preceded photostimulation, the time from the start of spermatogenesis to the appearance in the ejaculate being between 
13 and $15 \mathrm{~d}$ (de Reviers, 1968). Therefore, it would appear that the age at photostimulation had no influence on the mean age when semen production was first observed.

Table 1 Mean ( \pm s.e.) age at first semen production (d) of males photostimulated at different ages

\begin{tabular}{ccc}
\hline Age at photostimulation (d) & Mean age at first semen production (d) & s.e. \\
\hline 56 & 167 & 3.1 \\
77 & 165 & 2.2 \\
98 & 164 & 2.2 \\
119 & 170 & 1.4 \\
147 & 172 & 1.7 \\
161 & 164 & 4.7 \\
\hline
\end{tabular}

The age at which testis growth was most rapid $\left(\mathrm{t}^{*}\right)$ was earlier, in all cases, than the predicted age at $50 \%$ production in females, which was calculated as a more accurate indicator of sexual maturity in females than age at first egg, as not all pullets lay on consecutive days after the first egg (Lewis et al., 2007) (Figure 1). It appears as if males and females exhibit a similar response to photostimulation when using $t^{*}$ as an indicator of sexual maturity, rather than the age at which semen is first observed or produced, although $t^{*}$ is a measure of testis development, rather than sexual maturity. Although it may be expected that males would naturally reach sexual maturity before their female counterparts, the apparent earlier development may not necessarily be accompanied by the production of functional spermatozoa during the rapid growth phase - this aspect possibly being delayed until the testes have reached their mature weight.

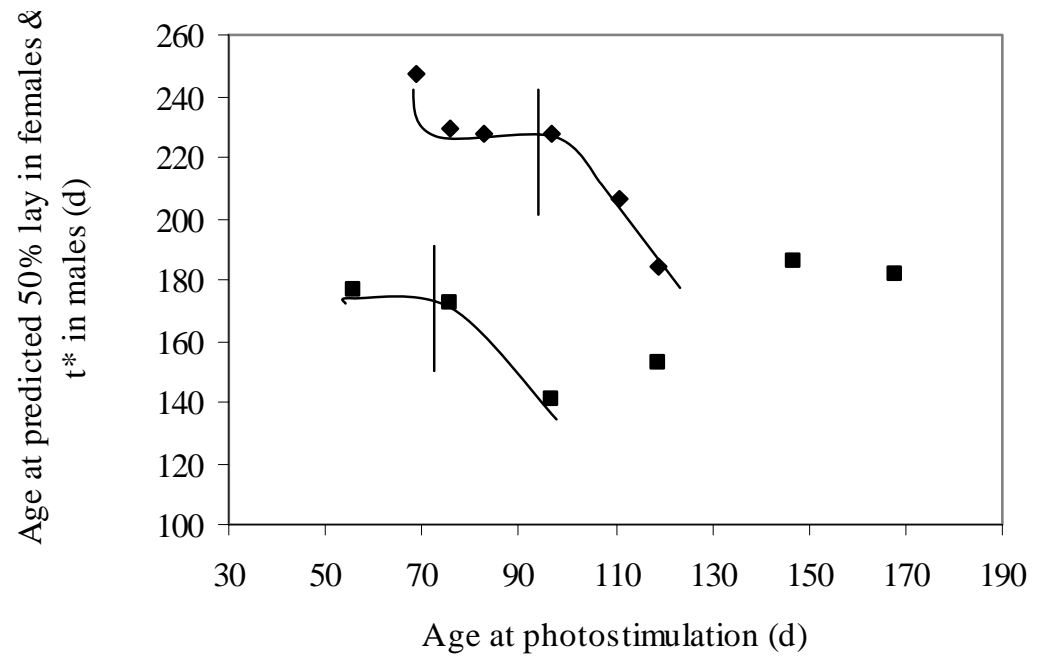

Figure 1 Estimated age at 50\% production of female broiler breeders ( $\bullet$ ) (Lewis et al., 2007) and the age at which testis growth was most rapid in male broiler breeders ( $\bullet$ ) photostimulated at different ages, with curves fitted by eye.

A difference in the pattern of response to photostimulation of males compared to females is that $t^{*}$ increases with photostimulation after $98 \mathrm{~d}$ (Figure 1). This is probably due to the initiation of the rapid 
growth phase before photostimulation. Therefore, regardless of age at photostimulation, testis growth will still be initiated, and these points are not in response to age at photostimulation, but rather to spontaneous maturation. In female broiler breeders, photostimulated after $130 \mathrm{~d}$, the response curve appears similar to that seen in males in Figure 1, where age at sexual maturity is delayed (Ciacciariello, 2003) and is thought to be due to spontaneous maturation and not as a result of lighting treatment. Because $t^{*}$ was similar for males photostimulated at 56, 77, 147 and $161 \mathrm{~d}$, it appears that photostimulation at 56 and $77 \mathrm{~d}$ was too early to elicit a photosexual response in most males. These males thus responded as if reared on $16 \mathrm{~h}$, while those photostimulated at 147 and $161 \mathrm{~d}$ initiated sexual development close to or before photostimulation.

For male broiler breeders across all treatments, the left testis weight was heavier than the right in $75.6 \%$ of the cases (Figure 2), which concurs with most reports (Hocking, 1992; Wolanski et al., 2004) and shows directional asymmetry (Møller, 1994). Møller (1994) also showed that, in barn swallows and house sparrows, the greater the directional asymmetry, in the form of a higher volume of the left testis compared to the right, the greater the phenotypic quality, as measured by the expression of the secondary sexual characteristics. Although this would be an added advantage in birds that have flight requirements, in this study, directional asymmetry was interpreted as a reliable indicator of developmental stability, as two large testes would have a higher immuno-suppressive cost of androgen production (Zuk et al., 1995) and the right testis was thought to play a more compensatory role, with symmetry resulting from an increased right testis, indicating a lower performance of the left testis.

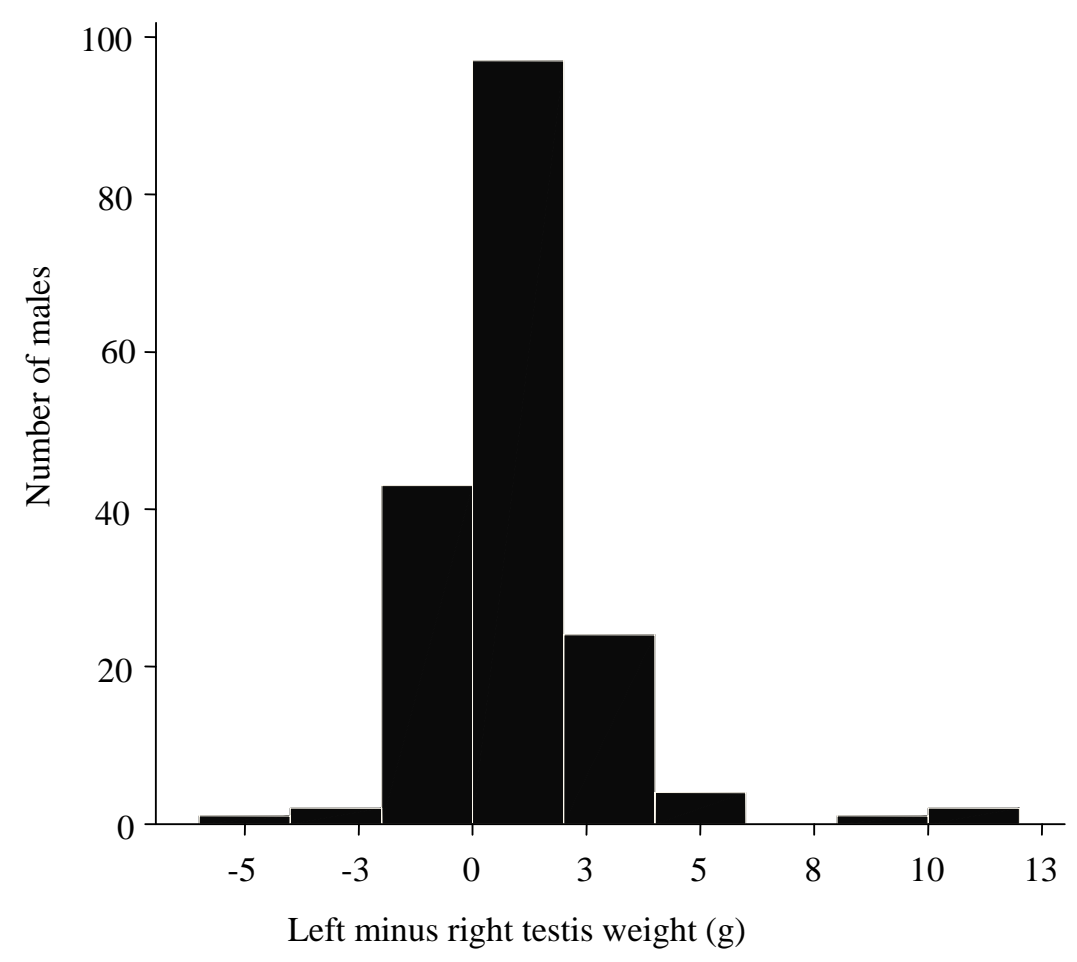

Figure 2 Directional asymmetry in testis weight of broiler breeder males photostimulated at different ages.

In chickens, McGary et al. (2003) found no overall relationship between degree of fluctuating asymmetry of the secondary sexual traits (wattle length, width and area) and male fertility potential, as measured by macroscopic assessment of the germinal disc and sperm penetration of the perivitelline membrane. However, greater dorsal pelvic width asymmetry in one strain was associated with lower estimated fertility, but it is not clear how pelvic width was considered to be a bilateral trait.

This is in contrast with other studies measuring morphological traits, which suggest that fluctuating asymmetry, as a measure of developmental stability, is a reflection of genetic or environmental stress, and has been suggested, and used, to measure genetic stress (Yang et al., 1997; Yang \& Siegel, 1998) and welfare and environmental stress (Møller et al., 1999; Yalcin et al., 2001) in poultry. 
The $\mathrm{L}$ and $\mathrm{R}$ testis weights were shown by the $t$-test to be significantly different for males on each treatment, except for those birds photostimulated at $161 \mathrm{~d}$, where the $\mathrm{L}$ and $\mathrm{R}$ testis weights were the same. The other bilateral traits measured also showed directional asymmetry, except for HL, which showed a skew distribution. There was no effect of photoperiodic treatment on the degree of RA of SL, SD or HL. Therefore it is hard to determine whether the directional asymmetry observed in testis weights is an adaptation advantageous to fertility, or whether all treatments other than photostimulation at $161 \mathrm{~d}$ impose developmental stress on the birds. This could also be the result of spontaneous testis development, rather than development in response to light.

Average testis weights clearly demonstrated that some birds respond to early stimulation while others on the same treatment remain photorefractory. Some birds photostimulated at 56 and $77 \mathrm{~d}$ recorded average testis weights above $2 \mathrm{~g}$ at $123 \mathrm{~d}$ of age, while the testis weights of birds photostimulated at $98 \mathrm{~d}$ and later remained below $2 \mathrm{~g}$ until $144 \mathrm{~d}$. However, after $189 \mathrm{~d}$, all males photostimulated at $98 \mathrm{~d}$ and later had an average testis weight $>10 \mathrm{~g}$, while the weights of those photostimulated at 56 and $77 \mathrm{~d}$ ranged from 1.61 to $15.58 \mathrm{~g}$. Thus, early photostimulation induced a photosexual response in some birds, while causing a more prolonged delay in others. Later photostimulation resulted in a more uniform response. This suggests that the variation in the genetic composition of broiler breeders is large, where some birds respond to very early light stimulation, while others remain photorefractory. While such early stimulation would not be recommended in practice, it would be useful to capitalise on the genetics of such birds as a means of eliminating photorefractoriness in broiler breeders.

While the males were fed to reach the target body weights recommended by the breeder, there was a normal distribution in the body weight of birds within a treatment, and there may also be an environmental effect of the response to light based on the degree of body reserves to allocate to testis development.

There was no photoperiodic effect on serum testosterone concentration which, from 123 to $224 \mathrm{~d}$, remained below $6 \mathrm{ng} / \mathrm{mL}$ for males on all treatments, except for two birds sampled at $137 \mathrm{~d}$ that recorded concentrations of $9.6 \mathrm{ng} / \mathrm{mL}$ (photostimulated at $77 \mathrm{~d}$ ) and $7.5 \mathrm{ng} / \mathrm{mL}$ (photostimulated at $98 \mathrm{~d}$ ). However, at $351 \mathrm{~d}$, near the end of the production cycle, the same variation in response to photoperiod observed when measuring t* was also evident (Figure 3), with birds photostimulated earlier than $119 \mathrm{~d}$ exhibiting either high or low serum testosterone concentrations, contrasting with a more even spread among males photostimulated at $119 \mathrm{~d}$ and later. It would be interesting to know whether early responders initiated gonadal regression earlier or later than non-responders towards the end of the season, as this could inform breeding companies of the value of selecting for responders among males.

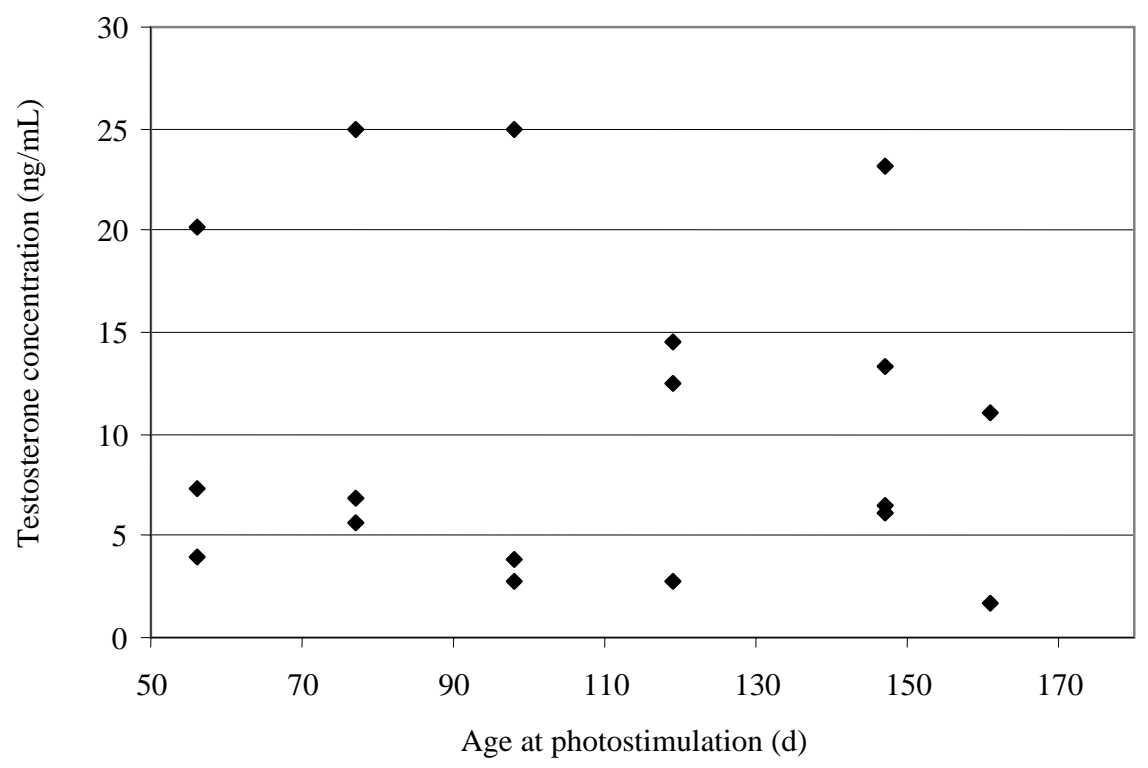

Figure 3 Serum testosterone concentrations of males at $315 \mathrm{~d}$ following photostimulation at different ages. 


\section{Conclusions}

Where male and female broiler breeders are reared on the same lighting programme, males are likely to attain sexual maturity before females, which is necessary to maximise fertility. All broiler breeder males should respond to photostimulation at $98 \mathrm{~d}$ or later, while some respond to earlier photostimulation. Such responders could be selected and utilised in a breeding programme to eliminate seasonality in broiler breeders. Such a genotype would be useful in production systems using open-sided houses, where short daylengths cannot be applied during the rearing period, resulting, at present, in differences in fertility between in-season and out-of-season flocks.

\section{Acknowledgements}

The authors would like to thank Ross Poultry Breeders in South Africa, and the NRF for a Thuthuka grant. Thanks also to M. Ciacciariello for comments on the final draft.

\section{References}

Aviagen, 2006. Parent Stock Management Manual. www.aviagen.com accessed Jan 2006.

Ciacciariello, M., 2003. The productive response of broiler breeder hens to lighting and growth manipulation during rearing. $\mathrm{PhD}$ thesis, University of Natal, South Africa.

De Reviers, M., 1968. Determination of the duration of the spermatogenic process in the cockerel using tritiated thymidine (in French). VI Cong. Intern. Reprod. Anim. Insem. Artif., Paris. 1, 183-185.

Dunn, I.C. \& Sharp, P.J., 1990. Photoperiodic requirements for LH release in juvenile broiler and egg-laying strains of domestic chickens fed ad lib or restricted diets. J. Reprod. Fert. 90, 329-335.

Dunn, I.C., Sharp, P.J. \& Hocking, P.M., 1990. Effects of interactions between photostimulation, dietary restriction and dietary maize oil dilution on plasma LH and ovarian and oviduct weights in broiler breeder females during rearing. Br. Poult. Sci. 31, 415-427.

Genstat, 2008. VSN International Ltd, $11^{\text {th }}$ ed., Hemel Hempstead, UK.

Hocking, P.M., 1992. Bilateral testicular asymmetry and supernumerary testes in the domestic fowl (Gallus domesticus). Br. Poult. Sci. 33, 455-460.

Lake, P.E., 1957. Fowl semen as collected by the massage method. J. Agric. Sci. 49, 120-126.

Lewis, P.D., Backhouse, D. \& Gous, R.M., 2004. Constant photoperiods and sexual maturity in broiler breeder pullets. Br. Poult. Sci. 45, 557-560.

Lewis, P.D., Ciacciariello, M., Backhouse, D. \& Gous, R.M., 2007. Effect of age and body weight at photostimulation on the sexual maturation of broiler breeder pullets transferred from 8L:16D to 16L:8D. Br. Poult. Sci. 48, 601-608.

Lewis, P.D., Ciacciariello, M., Ciccone, N.A., Sharp, P.J. \& Gous, R.M., 2005. Lighting regimens and plasma LH and FSH in broiler breeders. Br. Poult. Sci. 46, 349-353.

Lewis, P.D., Tyler, N.C., Gous, R.M., Dunn, I.C. \& Sharp, P.J., 2008. Photoperiodic response curves for plasma LH concentrations and age at first egg in female broiler breeders. Anim. Reprod. Sci. 109, 274-286.

McGary, S., Estevez, I. \& Bakst, M.R., 2003. Potential relationships between physical traits and male breeder fertility. Poult. Sci. 82, 328-337.

Mohan, J., Moudgal, R.P., Sastry, K.V.H., Tyagi, J. \& Singh, R., 2002. Effects of hemicastration and castration on foam production and its relationship with fertility in male Japanese quail. Theriogenology. 58, 29-39.

Møller, A.P., 1994. Directional selection on directional asymmetry: testes size and secondary sexual characters in birds. Proc. R. Soc. Lond. B 258, 147-151.

Møller, A.P., Sanotra, G.S. \& Vestergaard, K.S., 1999. Developmental instability and light regime in chickens (Gallus gallus). Appl. Anim. Behav. Sci. 62, 57-71.

Proudfoot, F.G., Hulan, H.W. \& McRae, K.B., 1984. Effects of photoperiod, light intensity and feed restriction on the performance of dwarf and normal maternal poultry meat genotypes. Can. J. Anim. Sci. 71, 1233-1239.

Robinson, F.E., Wautier, T.A., Hardin, R.T., Robinson, N.A., Wilson, J.L., Newcombe, M. \& McKay, R.I., 1996. Effects of age at photostimulation on reproductive efficiency and carcass characteristics. 1. Broiler breeder hens. Can. J. Anim. Sci. 76, 275-282. 
Tyler, N.C. \& Gous, R.M., 2008. The effect of constant photoperiod on testis weight and the use of comb area to predict testis weights in broiler breeder males. S. Afr. J. Anim. Sci. 38, 153-158.

Wolanski, N.J., Renema, R.A., Robinson, F.E. \& Wilson, J.L., 2004. End-of-season carcass and reproductive traits in original and replacement male broiler breeders. J. Appl. Poult. Res. 13, 451-460.

Yalcin, S., Özkan, L., Türkmut, L. \& Siegel, P.B., 2001. Responses to heat stress in commercial and local broiler stocks. 2. Developmental stability of bilateral traits. Br. Poult. Sci. 42, 153-160.

Yang, A. \& Siegel, P.B., 1998. Asymmetries and heterosis of bilateral traits in parental lines of chickens and their $\mathrm{F}_{1}$ crosses. J. Anim. Breed. Genet. 115, 105-111.

Yang, A., Dunnington, E.A. \& Siegel, P.B., 1997. Developmental stability in stocks of white leghorn chickens. Poult. Sci. 76, 1632-1636.

Zuk, M., Johnson, T.S. \& Maclarty, T., 1995. Endocrine-immune interactions, ornaments and mate choice in red jungle fowl. Proc. R. Soc. Lond. B 260, 205-210. 